\title{
Extracellular Electrical Fields Direct Wound Healing and Regeneration
}

\author{
MARK A. MESSERLI ${ }^{1,2, *}$ AND DAVID M. GRAHAM ${ }^{1}$ \\ ${ }^{1}$ The Eugene Bell Center for Regenerative Biology and Tissue Engineering and ${ }^{2}$ The Cellular Dynamics \\ Program, Marine Biological Laboratory, Woods Hole, Massachusetts 02543
}

\begin{abstract}
Endogenous DC electric fields (EFs) are important, fundamental components of development, regeneration, and wound healing. The fields are the result of polarized ion transport and current flow through electrically conductive pathways. Nullification of endogenous EFs with pharmacological agents or applied EFs of opposite polarity disturbs the aforementioned processes, while enhancement increases the rate of wound closure and the extent of regeneration. EFs are applied to humans in the clinic, to provide an overwhelming signal for the enhancement of healing of chronic wounds. Although clinical trials, spanning a course of decades, have shown that applied EFs enhance healing of chronic wounds, the mechanisms by which cells sense and respond to these weak cues remains unknown. EFs are thought to influence many different processes in vivo. However, under more rigorously controlled conditions in vitro, applied EFs induce cellular polarity and direct migration and outgrowth. Here we review the generation of endogenous EFs, the results of their alteration, and the mechanisms by which cells may sense these weak fields. Understanding the mechanisms by which native and applied EFs direct development and repair will enable current and future therapeutic applications to be optimized.
\end{abstract}

\section{Introduction}

The study of development and regeneration enhances our understanding of the natural mechanisms for the building and rebuilding of organisms, from the level of the single cell to the entire body plan. These processes involve complex

Received 16 February 2011; accepted 20 June 2011.

* To whom correspondence should be addressed. E-mail: mmesserli@ mbl.edu

Abbreviations: EF, electric field; ES, electrical stimulation; TEP, transepithelial potential. interactions between the chemical and physical realms. Research over the last few decades has helped elucidate the strong dependence on the complex orchestration of multiple gene products in space and time. However, it still remains very difficult to alter the expression of genes to rebuild damaged tissue in humans, especially when considering the use of controversial treatments such as gene therapy. A systems-based view of development and regeneration may provide suitable therapeutic alternatives. Complex interactions of multiple gene products give rise to physical cues, including mechanical and electrical signals that are relatively easier to control and implement to guide repair and regeneration. We direct our discussion to the role of extracellular electrical fields (EFs) and their roles in controlling development, wound healing, and regeneration.

An electric field (EF) is an electrical potential difference between two points a known distance apart, measured in units of volts per distance. In a conductive medium an EF results in current flow, and current flow generates an EF. The current is carried by ionized species in the medium, mostly inorganic ions, the predominant charged species. EFs depend on the presence of a voltage source (battery) and a conductive pathway. The two predominant DC voltage sources in biological organisms are the trans-plasma membrane electrical potential and the trans-epithelial potential (TEP) that exists across sheets of cells connected via high-resistance tight junctions. Injury to the high-resistance structures, the plasma membrane or tight-junctional epithelium, creates a lower resistance pathway, short-circuiting the battery and giving rise to current flow at the site of injury. As a result, cells in the local vicinity, involved in the wound healing process, are instantly exposed to a strong and long-lasting directional signal.

The first measurements of injury currents near human skin wounds were reported over a century ago (du Bois- 
Reymond, 1860; Herlitzka, 1910). Over the last few decades interest has been renewed for understanding (1) the physiological basis of the injury currents, (2) their role in development, regeneration, and repair, (3) optimization of applied EFs in the clinic to promote healing and regeneration, and (4) the mechanisms by which cells sense these weak EFs and control the downstream signaling pathways used to direct cellular responses. We review each of these areas to point out similarities, identify points of contention, and stimulate new directions for inquiry.

\section{Generation of Endogenous Electric Fields}

Endogenous extracellular DC EFs are generated by polarized ion transport and conductive extracellular pathways. In the first examples to be discussed, the conductive pathways are created as a result of injury. However, in the further examples in which EFs exist during embryonic development, the conductive pathways are made naturally and are not due to injury. Polarized ion transport, which leads to net movement of charge, creates electrical potential differences, a battery, across high-resistance structures such as the apical to basolateral sides of sheets of cells connected via high-resistance tight junctions-for example, epithelia (Fig. 1A, B) - and the plasma membrane of cells (Fig. 1D, E). In both of these examples, net charge transport, predominantly by the electrogenic $\mathrm{Na}^{+}-\mathrm{K}^{+}$ATPase $\left(3 \mathrm{Na}^{+}: 2 \mathrm{~K}^{+}\right)$, gives rise to the electrical potential differences. A TEP of around $+50 \mathrm{mV}$ is maintained across the epidermal epithelium by net positive charge transport across the apical to basolateral membranes via localization of the basolateral $\mathrm{Na}^{+}-\mathrm{K}^{+}$ATPase (Fig. 1B). $\mathrm{Na}^{+}$influx through apical $\mathrm{Na}^{+}-$ channels maintains homeostatic levels of cytosolic $\mathrm{Na}^{+}$. $\mathrm{Cl}-$ efflux from the apical membrane may also help to generate the internally positive TEP (Reid et al., 2005). The trans-plasma membrane potential of neurons is near $-70 \mathrm{mV}$ owing to the net positive charge transport out of the cell by the $\mathrm{Na}^{+}-\mathrm{K}^{+}$ATPase and the electrochemical equilibrium of $\mathrm{K}^{+}$and resting conductance of $\mathrm{K}^{+}$channels (Fig. 1E). Damage to the high-resistance structures leads to shortcircuiting of the electrical potential differences and production of extracellular current. Current flow, represented as the movement of positive charge, is shown by arrows near a wounded, non-keratinized epithelium in Figure 1C, and a transected neuron in Figure 1F. The center of the epithelial wound is electrically negative with respect to the undamaged regions at the same layer surrounding the wound. The current lines near the transected neuron enter the injured cell, driven by the internally negative membrane potential.

\section{Injured epidermal epithelium}

Injury to the epidermis causes a short circuit of the TEP, giving rise to a measured DC current efflux between 1 and $10 \mu \mathrm{A} / \mathrm{cm}^{2}$ and an estimated current density up to 300 $\mu \mathrm{A} / \mathrm{cm}^{2}$ near the edge of the wound (Barker et al., 1982; Zhao et al., 2006). The currents generate relatively steady local electric fields between 40 and $200 \mathrm{mV} / \mathrm{mm}$ (Barker et al., 1982; McGinnis and Vanable, 1986; Chiang et al., 1989, 1992; Sta Iglesia et al., 1996; Sta Iglesia and Vanable, 1998) that decay over hours and can still be measured for at least $24 \mathrm{~h}$ after injury. Amputation of digits or limbs is an even greater insult to the epidermis. Current flow is generated by the remaining epidermal epithelium and exits the low-resistance site of amputation. Currents from amputated newt limbs range between 10 and $100 \mu \mathrm{A} / \mathrm{cm}^{2}$ and peak a few days after amputation (Borgens et al., 1977b). Currents measured from the finger tips of amputees reach a measured peak current density of $22 \mu \mathrm{A} / \mathrm{cm}^{2}$ after an average of 8 days (Illingworth and Barker, 1980). The range of field strengths measured near epidermal wounds or inferred from current density measurements is at least an order of magnitude below the EF strength employed by many common applications of EFs in the research laboratory (Fig. 2), and is an order of magnitude greater than the threshold field strength that cells sense and respond to in culture. For comparison, the threshold field strength is about 500 times smaller than the field strength necessary to lead to depolarization and contraction of skeletal muscle and is 4500 times smaller than the minimum field strength necessary to electroporate skeletal muscle (Gehl et al., 1999; Posterino et al., 2000).

\section{Embryonic epidermal epithelium}

Electric fields and current flux have also been mapped in developing embryos to which no injury has been performed. Electrical polarization of the embryonic epidermal epithelium occurs very early in development. In Xenopus the epithelium becomes polarized between gastrulation and neurulation; current influx, ranging from 0.1 to several $\mu \mathrm{A} / \mathrm{cm}^{2}$, occurs over the entire surface of the embryonic epidermal epithelium; and substantially greater current efflux occurs through the low-resistance path of the blastopore, the opening to the primitive gut (Robinson and Stump, 1984). The endogenous EFs, measured beneath the epidermal epithelium, increase in magnitude near the blastopore, averaging $27 \mathrm{mV} / \mathrm{mm}$ between a point near the blastopore and a point $400-600 \mu \mathrm{m}$ rostral and $40 \mathrm{mV} / \mathrm{mm}$ between a point near the blastopore and a point $250 \mu \mathrm{m}$ dorsal at the caudal region of the embryo (Hotary and Robinson, 1994). The blastopore is electrically negative compared to the measured regions farther away. In chicks and mice, electrical currents have been mapped leaving the primitive streak, a site considered equivalent to an elongated blastopore (Jaffe and Stern, 1979; Winkel and Nuccitelli, 1989). Later in development, programmed cell death gives rise to a low-resistance pathway and current efflux at the posterior intestinal portal (pip), the opening into the hindgut from the 

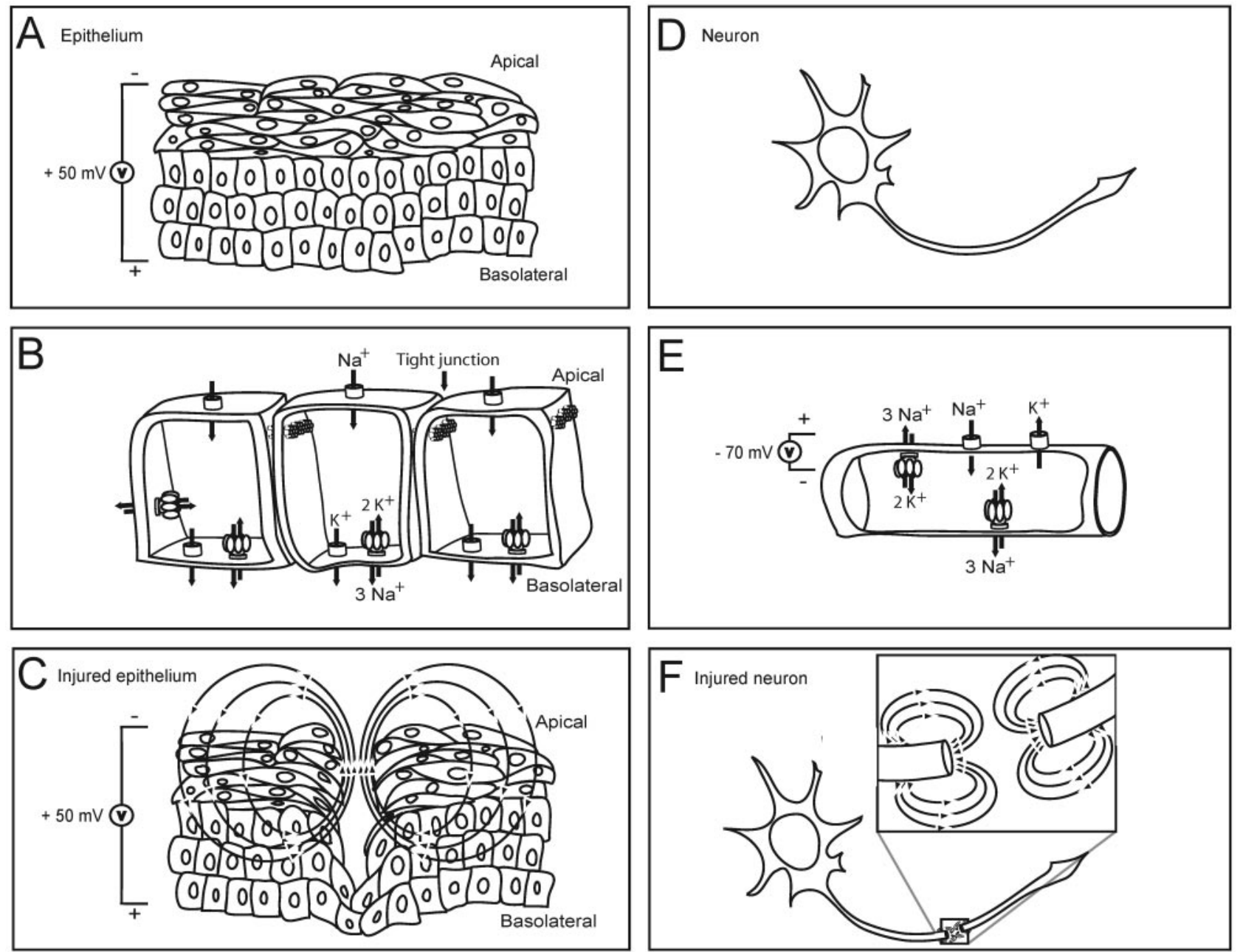

Figure 1. Generation of endogenous electrical potentials and injury currents. (A) A non-keratinized epidermal epithelium composed of an apical squamous and basolateral cuboidal layer is illustrated with a transepithelial electrical potential of $+50 \mathrm{mV}$. (B) A section of the cuboidal layer where single epithelial cells, connected by tight junctions, prevent free diffusion of ions or current flow between the apical to basolateral surfaces. Polarized ion transport across tight-junction-connected single cells gives rise to net movement of positive charge and generates an electrical potential difference. Here, the basolateral localization and activity of the electrogenic $\mathrm{Na}^{+}-\mathrm{K}^{+}$ATPase is primarily driving the net charge movement across connected cells. (C) An injured epidermal epithelium gives rise to a low-resistance pathway, short-circuiting the epithelial battery and generating current flow near the site of injury. The arrow direction indicates the movement of positive charge. (D) A neuron with cell body and extending axon. (E) Cross-section of the axon depicting a resting membrane potential of $-70 \mathrm{mV}$ generated primarily by the electrogenic $\mathrm{Na}^{+}-\mathrm{K}^{+}$ATPase. (F) Injury gives rise to a low-resistance pathway, and electrical current (movement of positive charge) is directed into the cell, indicated by the arrows.

yolk sac. In chick embryos, the current peaks at $112 \mu \mathrm{A} /$ $\mathrm{cm}^{2}$ at stage 17, with measured EFs at the caudal end of the embryo averaging $21 \mathrm{mV} / \mathrm{mm}$ at the same stage (Hotary and Robinson, 1990).

\section{Injured neurons}

Extracellular electrical fields near clusters of damaged neurons can extend millimeters away from the injury site and continue for days. Currents around a single transected neuron are shown for clarity in Figure 1F. Current influx peaks at a few hundred microamperes per square centimeter immediately after transection or crush of lamprey and guinea pig spinal cords (Borgens et al., 1980; Zuberi et al., 2008). In lamprey, the rapid decrease in current occurs within the first $2 \mathrm{~h}$ and then slowly declines, remaining at 4 $\mu \mathrm{A} / \mathrm{cm}^{2}$ for up to the 6 days after injury that it was measured (Borgens et al., 1980). Current density of $20 \mu \mathrm{A} / \mathrm{cm}^{2}$ remained for up to $6 \mathrm{~h}$ after injury in guinea pig spinal cord 


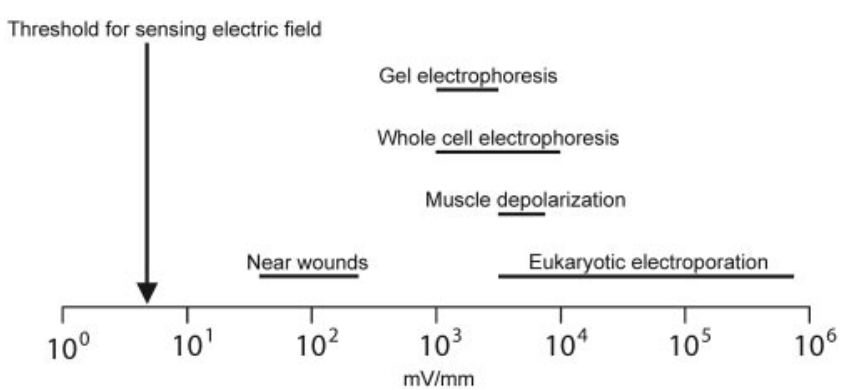

Figure 2. Range of electric field strength generated by injury currents compared to EF strength used for common scientific purposes. Field strengths have been normalized to millivolts per millimeter. Endogenous EFs are considered weak compared to the high field strengths used by various scientific instrumentation.

explants (Zuberi et al., 2008). Assuming saline resistivity of $100 \Omega \mathrm{cm}$, extracellular EFs of $40 \mathrm{mV} / \mathrm{mm}$ and $200 \mathrm{mV} / \mathrm{mm}$ would exist around these injured neurons for an extended time.

\section{Response of Cells to DC Electric Fields in vitro}

Identification of the weak DC EFs induced by injury prompted the question of whether they could have any effect on surrounding cells and tissues. As a result, many different types of cultured cells have been exposed to EFs, and the effects on the cells have been characterized. Only cells that were exposed to field strengths similar to those measured in the systems described above will be discussed.

Cultured vertebrate cells commonly respond to weak DC EFs by aligning, migrating, or growing along a direction with respect to the EF lines. Many reports describe that the long axis of cells becomes aligned perpendicular to the EF lines; such alignment has been observed in cells including osteoblasts and osteoclasts (Ferrier et al., 1986), epidermal keratinocytes (Cooper and Schliwa, 1986; Nishimura et al., 1996; Chernyavsky et al., 2005; Huang et al., 2009), corneal epithelial cells (Zhao et al., 1996), neural crest cells (Cooper and Keller, 1984), astrocytes (Borgens et al., 1994; Alexander et al., 2006) endothelial cells (Zhao et al., 2004), prostate cancer cells (Djamgoz et al., 2001), chondrocytes (Chao et al., 2000), fibroblasts (Chao et al., 2007), and muscle (Hinkle et al., 1981; McCaig and Dover, 1991). The plane of cell division is aligned perpendicular to the EF lines as reported for corneal epithelia cells (Zhao et al., 1999b). Most of the examples listed above are also motile and migrate toward the cathode in an applied EF. However, a few exceptions migrate toward the anode, including osteoclasts (Ferrier et al., 1986), dermal fibroblasts (Guo et al., 2010), and Schwann cells (McKasson et al., 2008). These examples make excellent targets for study in helping to identify the mechanisms by which cells sense and respond to weak EFs when used in comparison with a cathode-directed cell type. The threshold of the EF-directed responses for epidermal cells is $\sim 7 \mathrm{mV} / \mathrm{mm}$ (Nishimura et al., 1996; Huang et al., 2009) and for Schwann cells is $\sim 3$ $\mathrm{mV} / \mathrm{mm}$ (McKasson et al., 2008).

The polarized responses of epidermal cells in culture are consistent with the direction of the EFs near wounds. Cells align their long axis perpendicular to the field lines (Fig. $3 \mathrm{~A}$ ), which are tangent to the edge of a wound. Human keratinocytes and zebrafish epidermal keratocytes migrate toward the negative pole, which is toward the center of the wound, under DC fields of physiological magnitude (Nishimura et al., 1996; Zhao et al., 2006; Huang et al., 2009). Cultured zebrafish keratocytes display a cathodal response to applied EFs that varies with magnitude (Fig. 3B, C). The measurement of the cosine $\theta$ indicates the direction of migration: -1 indicates that $100 \%$ of cells are migrating toward the cathode and +1 indicates that $100 \%$ of cells are migrating toward the anode. A value near zero indicates relatively random migration. Sheets of cells have a sensitivity to EFs and migratory responses similar to those of single cultured cells (Fig. 3B). The migration paths of many cells, immediately after application of EFs of differing magnitude, display an increase in the rate of turning with greater field strength (Fig. 3C). Additionally, the division plane of corneal keratocytes is perpendicular to the field lines such that subsequent cell divisions are expanding the cell sheet toward the center of the wound (Song et al., 2002). Accompanying the directed migratory responses of human keratinocytes to applied EFs are changes in gene expression in which an increase in transcripts occurs for a host of inflammatory response genes and signaling genes (Jennings et al., 2010).

There are reports regarding the lack of response of fibroblasts to DC EFs that have recently been clarified. Sillman et al. (2003) reported that human dermal fibroblasts do not show directed migration in response to DC EFs of 100 $\mathrm{mV} / \mathrm{mm}$ after $1 \mathrm{~h}$ of application. Similarly, Godbout and Frenette (2006) reported that rat primary fibroblasts show no directed migration by EFs when alternating DC EFs of 10-m duration were used with a 10-m break between alternating EF polarities. More recently, Guo et al. (2010) confirmed the earlier findings of Sillman et al. (2003), but they also reported that primary fibroblasts show significant migration after EF application in vitro after $2 \mathrm{~h}$. They reported that injury currents near wounds last longer than $5 \mathrm{~h}$, so an endogenous EF may still direct migration in vivo. The slow migration rate of the cells, $\sim 15 \mu \mathrm{m} / \mathrm{h}$, makes it difficult to track migration over short periods of time. To respond in less than $2 \mathrm{~h}$, these cells appear to require field strengths greater than $100 \mathrm{mV} / \mathrm{mm}$, which do exist in vivo (Guo et al., 2010).

Unlike migratory cells, neurites respond to EFs in vitro in ways that vary considerably: their more complex responses to EFs have been called "bewildering" (reviewed in McCaig et al., 2005). In brief, early reports of exposing cultured 

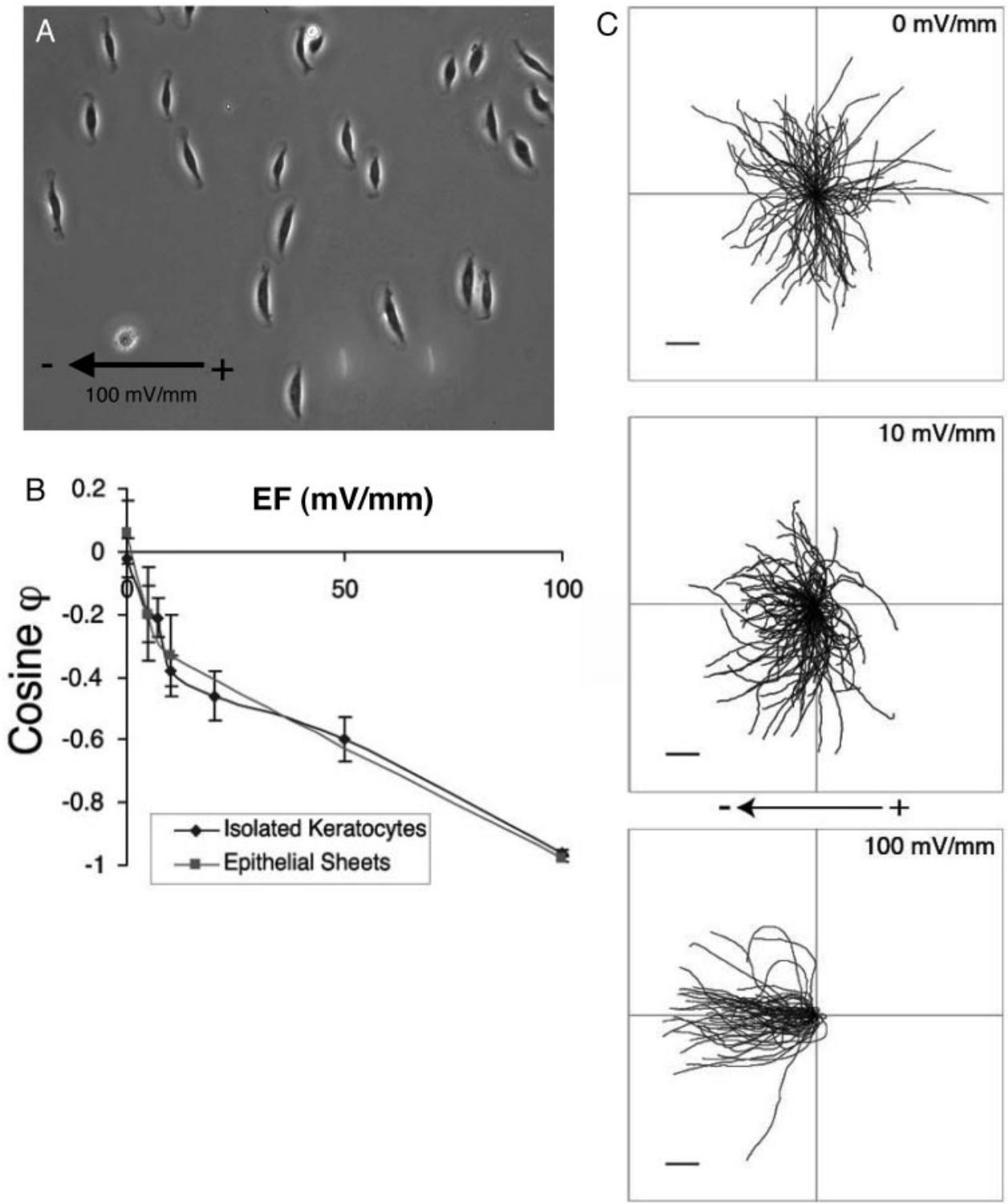

Figure 3. Electric fields direct migration of zebrafish keratocytes. (A) Photograph of migrating keratocytes after application of an EF of $100 \mathrm{mV} / \mathrm{mm}$. Cells align perpendicular to the EF lines and migrate toward the cathode (Huang et al., 2009). (B) A higher degree of polarization and directed migration occur with increasing field strength. Both single cells and cell sheets migrate toward the cathode with a sensitivity of $7 \mathrm{mV} / \mathrm{mm}$. The cosine $\theta$ measures the extent to which the cell population migrates toward the cathode $(-1)$ or the anode $(+1)$. Values near zero indicate relatively random migration. (C) Plots of the paths of migration for different cells exposed to different field strengths. The starting points of migration have been normalized to the origin. Migration into all four quadrants is shown for cells migrating in the absence of an EF, indicating random migration. Directed migration to the left, $2^{\text {nd }}$ and $3^{\text {rd }}$ quadrants, increases with increasing field strength.

neurites to applied EFs argued between enhanced cathodal outgrowth (Ingvar, 1920, 1947) and decreased anodal outgrowth (Weiss, 1934; Williams, 1936; Marsh and Beams, 1946). Later it was reported that chick neurites grew faster toward the cathode than the anode, with no obvious turning involved (Jaffe and Poo, 1979). During reversal of EF polarity it was noted that neurites grew faster on the new cathode side but retracted on the anodal side. Cultured
Xenopus spinal neurites show enhanced cathodal initiation, cathodal growth, cathodal turning, cathodal branching, and anodal retraction (Hinkle et al., 1981; Patel and Poo, 1982; McCaig, 1987, Rajnicek, 1998). The threshold of the EFdirected responses for Xenopus neurites is $\sim 7 \mathrm{mV} / \mathrm{mm}$ (Hinkle et al., 1981; Patel and Poo, 1982). While much has been learned from studying Xenopus spinal neurites, other neurites have been shown to respond to EFs in different 
manners. Zebrafish spinal neurites grown on laminin do not respond to external EFs of $100 \mathrm{mV} / \mathrm{mm}$ (Cormie and Robinson, 2007), unlike Xenopus spinal neurites grown on laminin, which show significant initiation, turning and branching toward the cathode at the same field strength (Rajnicek et al., 1998). Neurites from PC12 cells grow toward the anode (Cork et al., 1994). Other examples, including rat hippocampal neurites (Rajnicek et al., 1992) and chick post sympathetic neurons (Pan and Borgens, 2010), grow perpendicular to EF lines. Focally applied EFs induced presumptive dendrites of embryonic rat hippocampal neurons to grow toward the cathode but had no effect on presumptive axons (Davenport and McCaig, 1993). The varying responses of neurites in culture from different organisms and preparations have led to criticism of the use of in vitro studies to guide optimization of EF-directed neuronal repair in humans (Robinson and Cormie, 2008).

\section{Modification of Endogenous Electric Fields}

Characterizing the response of cells to EFs in vitro has only helped identify possible roles for EFs in vivo. However, alteration of the endogenous EFs has provided convincing evidence to support their role in development, wound healing, and regeneration. As mentioned above, the embryonic epidermal epithelium forms early in Xenopus development, and the current flow generated through the embryo by the electrical potential across the epithelium exits the blastopore (Robinson and Stump, 1984; Hotary and Robinson, 1994). Experiments that altered that current flow through the developing embryo produced developmental abnormalities along the entire body axis. A microelectrode was impaled in the flanks of the embryos and current was passed so that the net current flux through the blastopore was reversed (Hotary and Robinson, 1994). These embryos developed a great degree of abnormality in 20 of 23 embryos, while 3 developed normally. For comparison, in embryos that had been impaled with a microelectrode but received a current 10 times lower or no current, only 1 of 14 embryos developed abnormally. Embryos that were impaled and allowed to maintain normal blastopore currents developed normally (Fig. 4, top), while those in which the blastopore currents were reversed developed abnormally (Fig. 4, bottom). Abnormalities in the region of the head $(\mathrm{H})$, spinal cord, and tail (T) are obvious. In addition, ectopic cement glands were found in some embryos. Similar current disruption was performed in developing chick embryos. In that case the TEP was shunted along the flank of the embryo, which reduced currents exiting the posterior intestinal portal (pip) and also led to developmental abnormalities of the head and tail (Hotary and Robinson, 1992). Interestingly, a mutant chick line, rumpless, was identified that showed a similar phenotype in abnormal tail development. Rumpless embryos that developed abnormally possessed significantly

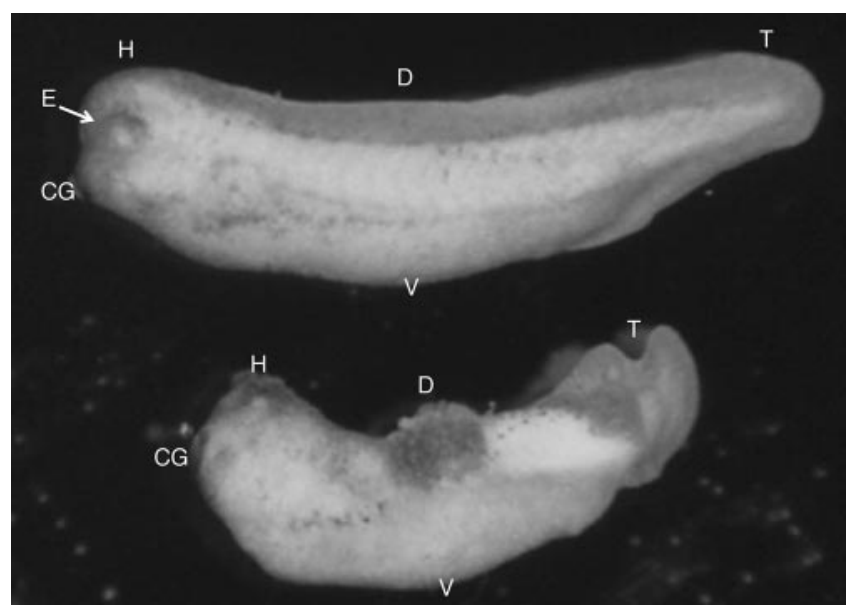

Figure 4. Disruption of endogenous embryonic currents impairs development in Xenopus. A normal embryo (top) develops when wholeembryo currents are not disrupted. This stage 33 embryo displays typical development of the head $(\mathrm{H})$, tail $(\mathrm{T})$, eye (E), and cement gland (CG). The fin on the dorsal (D) side of the embryo occurs with a normal ventral (V) region. In an embryo where blastopore currents have been reversed (bottom) the head is small, no eyes have developed, the dorsal fin is missing, and no spinal cord is apparent on the dorsal side. The tail is short and malformed.

reduced current efflux through the pip compared to wild type and rumpless embryos that did not show abnormal tail development (Hotary and Robinson, 1992).

Modification of endogenous injury currents also affects wound healing. Reduction or nullification of endogenous EFs retards wound healing (Rajnicek et al., 1988; Rhodes et al., 1990; Chiang et al., 1991). Enhancement and reduction of endogenous fields with pharmacological agents that alter the epithelial battery produced increased and decreased rates of healing, respectively, on injured rat cornea (Song et $a l .$, 2002). Increased rates of wound healing could be rescued by application of exogenous current after pharmacological inhibition of endogenous fields (Chiang et al., 1991; Sta Iglesia et al., 1996; Sta Iglesia and Vanable, 1998). Applied current used to enhance the magnitude of the injury currents in the bovine cornea increases the rate of wound closure (Sta Iglesia and Vanable, 1998). Interestingly, reversing the polarity of the endogenous EFs with applied current also increased the rate of wound closure (Sta Iglesia and Vanable, 1998). Although this result is difficult to explain on the basis of the in vitro work discussed above, similar efforts using reversal of polarity have been shown effective in clinical trials (discussed further below). Together these results support the role of endogenous DC electric fields in promoting wound healing in vivo.

Electrical currents exit sites of amputation and, like surface wounds, are generated by the surrounding epidermal epithelium (Borgens et al., 1977b; Illingworth and Barker, 1980; McGinnis and Vanable, 1986). Reduction of current efflux from amputated salamander and newt limbs by re- 
ducing the epithelial battery with pharmacological agents increased the number of animals that did not regenerate or showed deficient regeneration. Reduction of the epithelial battery by removing $\mathrm{Na}^{+}$from the animals' pond water delayed regeneration for weeks compared to controls (Borgens et al., 1979a). Reduction or nullification of limb currents by applying current in the opposite direction inhibited or gave rise to abnormal regeneration in $50 \%$ of animals (Jenkins et al., 1996). Grafting skin over the amputation site reduced the injury currents significantly and prevented regeneration (Altizer et al., 2002). Interestingly, the epidermal cells of newts possess a pre-existing sensitivity to extracellular EFs. Electrical stimulation of the epidermal epithelium in newts causes cells to dedifferentiate in the absence of amputation and in a manner that is not distinguishable from dedifferentiation after amputation (Atkinson et al., 2006).

While removal of endogenous currents inhibits regeneration, can enhancement of endogenous currents promote regeneration? This question was addressed in frog models, systems that can only partially regenerate limbs. A cartilagenous spike with little bone and few neurons regenerates from the site of amputation of sham-treated controls. However, enhancement of current efflux through the core of the limb at the amputation site enhanced regeneration (Borgens et al., 1977a, 1979b). The current-treated animals showed 40-fold enhanced innervation and bone structures and flattened bifurcated distal structures like the digits on a hand (Borgens et al., 1979b). The role of applied EFs in influencing nerve outgrowth in vivo is not limited to limb regeneration: the extent of neuronal sprouting and growth was correlated to EF strength during wound healing in the cornea (Song et al., 2004).

Based on the remarkable finding that increasing endogenous EFs promotes enhanced innervation in regenerating frog limbs, further experiments were performed to determine whether they could direct nerve regrowth after spinal cord injury. Reports showed that applied EFs increased the rate of functional recovery in the spinal cord of lamprey after transection (Borgens et al., 1981) and improved functional connections after spinal injury in rats (Fehlings et al., 1988), guinea pigs (Borgens et al., 1986; Borgens et al., 1987), and dogs (Borgens et al., 1999). These experiments have led to the first clinical trials of applied EFs to treat human spinal cord injury (Shapiro et al., 2005). However, these efforts are still in their infancy with this single phase I trial; therefore we consider it premature to review the topic at this time.

\section{Treatment of Human Chronic Wounds with Applied Electric Fields}

The investigations of the role of EFs during wound healing and regeneration, discussed above, were prompted by positive clinical trials of the healing of chronic wounds in humans. Chronic wounds are wounds that do not heal within 30 days. They afflict the elderly, people with diabetes, or those who are bedridden or immobilized, including those with paraplegia or quadriplegia. One of the first clinical studies to treat chronic wounds involved application of DC fields such that the cathode was placed on the surface of the wound (Wolcott et al., 1969). This would have resulted in the enhancement of the native EF. However, after a number of days when regrowth reached a plateau, the polarity of the $\mathrm{EF}$ was reversed. When a second plateau in regrowth was reached, the polarity of the EF was again reversed. Similar treatments with DC EFs were proved successful in other trials (Gault and Gatens, 1976; Carley and Wainapel, 1985). Later clinical trials employed pulsed DC EFs using a variety of waveforms rather than continuous DC EFs, with similar positive results (reviewed in Gardner et al., 1999; Kloth, 2005; Watson, 2008). Pulsed EFs commonly have a timeaveraged DC component. Of special note, AC EFs have been used with mixed results. Whereas an early report showed a significant yet subtle increase in the rate of healing (Lundeberg et al., 1992), a second study showed no significant effect (Baker et al., 1997). At that point electrical stimulation (ES) became the term for the many different forms of applied EFs used to enhance wound healing. Table 1 lists examples of some primary waveforms and the ranges of the parameters that have been used to enhance wound healing with ES, reflecting the complexity and variation of

Table 1

Electrical stimlation protocols

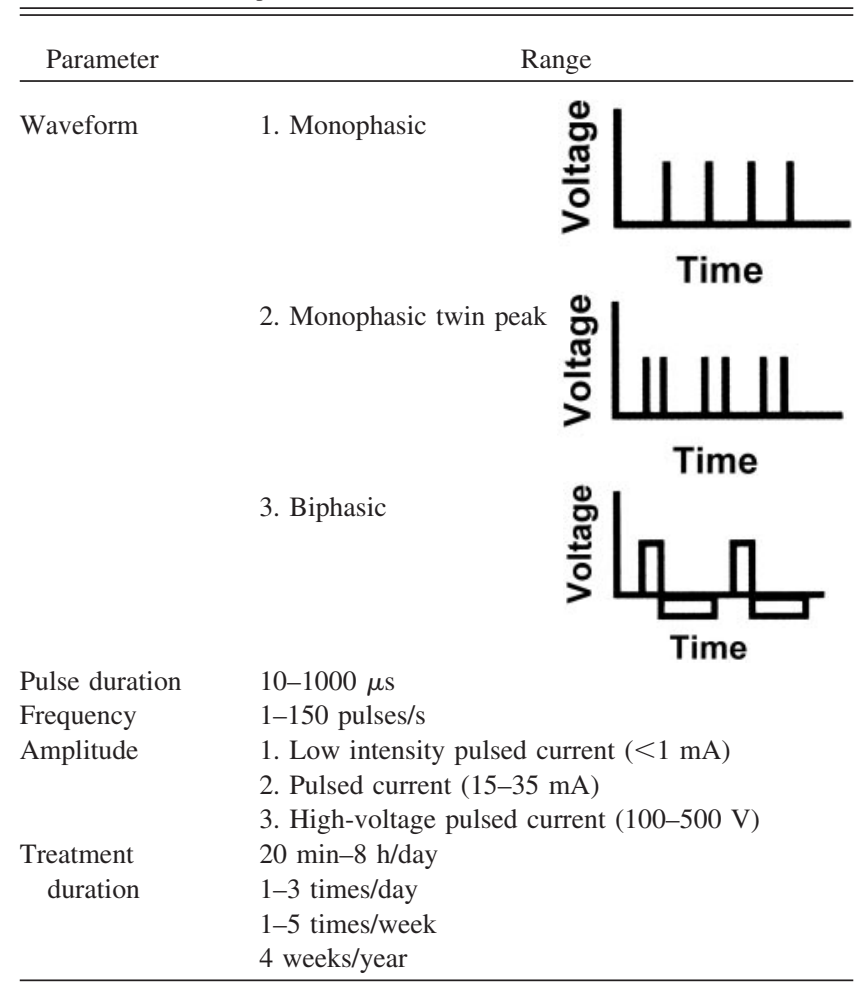


different treatments. A meta-analysis of 15 clinical trials spanning 26 years reported that on average ES increases the rate of wound healing of chronic wounds by 2.4 -fold compared to controls but that the relative effectiveness of different ES treatments was inconclusive (Gardner et al., 1999). In many cases, complete closure of chronic wounds that did not respond to other standard treatments was reported after treatment with ES. All together these clinical trials and scientific studies gave rise to a positive coverage decision in 2002 by the U.S. Department of Health and Human Services to use ES to treat chronic wounds including Stage III and Stage IV pressure ulcers, arterial ulcers, diabetic ulcers, and venous stasis ulcers.

Many mechanisms have been proposed to describe how ES promotes wound closure (reviewed in Kloth, 2005; Watson, 2008). However, at present it is not even clear how cells sense DC EFs or the very brief pulses associated with ES. Are all of these different forms of treatment necessary? How can treatments be optimized or simplified? The answers may be found in understanding how cells first sense EFs.

\section{Proposed Mechanisms for Sensing of Weak DC Electric Fields}

The polarizing responses of cells to weak EFs are thought to comprise, first, sensing the EFs; second, transduction of that (those) signal (or signals) into reorganization of cellular morphology. Multiple downstream signaling molecules that are involved with other aspects of directed migration have been identified (reviewed in McCaig et al., 2005; Zhao, 2009) and may eventually lead to identification of the upstream EF sensors. Sensing of the external EF still remains controversial and may be the easiest component to manipulate in order to redirect cellular responses. The generally accepted hypothesis on the sensing of EFs is that the extracellular electrical potential gradient across a cell generates an asymmetric signal between the two poles of the cell parallel to the EF lines. Of course, this difference in electrical potential is very small. The threshold field strength of $7 \mathrm{mV} / \mathrm{mm}$ across a $20-30-\mu \mathrm{m}$ diameter migratory cell produces only a difference of $0.1-0.2 \mathrm{mV}$ between the extreme edges of the cell along a line parallel to the EF. Epidermal cells respond to fields of this strength in less than 15 min (Nishimura et al., 1996; Huang et al., 2009). Two hypotheses (Fig. 5) have been formulated that describe how cells may perceive this asymmetric potential (reviewed in Robinson, 1985; McCaig et al., 2005; Levin, 2007). The first hypothesis (Fig. 5A, B) asserts that the EF exerts forces on freely diffusing signaling molecules on the extracellular surface. The net result of these forces leads to asymmetric redistribution of these signaling molecules and directed migration (McLaughlin and Poo, 1981). The second hypothesis (Fig. 5C, D) suggests that the EF induces asymmetric
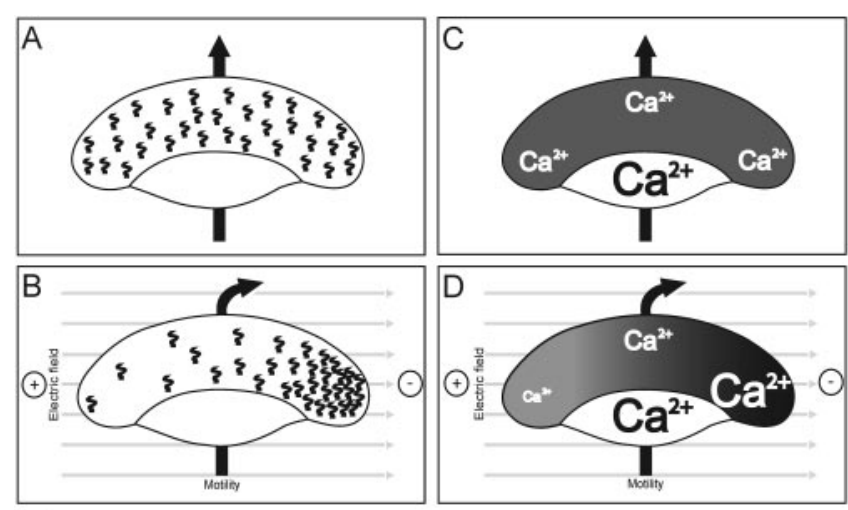

S Plasma mentrane bound mascomobecule

Figure 5. Mechanisms by which applied EFs generate cellular signaling gradients that direct migration. (A) In the absence of an EF, cell-surface signaling receptors are generally scattered homogenously over the surface of a migrating keratocyte. The arrow indicates direction of migration. (B) Cell-surface molecules become asymmetrically redistributed in the presence of an EF owing to the net force of electrophoresis and electro-osmosis. Electro-osmosis appears to dominate in driving surface molecules toward the cathode. Redistribution of these signaling molecules may direct cathodal migration. This model does not fully explain those few cases of cells that migrate toward the anode. (C) A migrating fish keratocyte in the absence of an EF possesses a higher $\left[\mathrm{Ca}^{2+}\right]_{\mathrm{i}}$ in the trailing cell body than in the extended lamellipodium. (D) The electrical potential gradient that exists across the cell in an applied EF may increase activation of voltage-gated $\mathrm{Ca}^{2+}$ channels on the cathodal side and decrease activation on the anodal side. This asymmetric signal may give rise to a gradient of intracellular $\mathrm{Ca}^{2+}$ that alters cell morphology and directs cathodal migration.

activation of a plasma membrane voltage sensor such as a voltage-gated $\mathrm{Ca}^{2+}$ channel (reviewed in Robinson, 1985) or other transplasma membrane voltage sensor (reviewed in McCaig et al., 2005; Levin, 2007). Asymmetric activation of this voltage sensor leads to a polarizing signal that directs changes to cell morphology and controls other cellular responses.

\section{Redistribution of cell-surface receptors}

Asymmetric redistribution of surface membrane components by weak DC EFs was first postulated by Jaffe (1977) and shown by Poo and Robinson (1977). As most surface molecules have a net negative charge at physiological $\mathrm{pH}$, an applied EF would generate an electrophoretic force that would cause them to migrate toward the positive anode (Fig 6 , top). Paradoxically, all the proteins that were visualized under normal conditions localized to the opposite side of the cell, the negatively charged cathode, as if they were positively charged, including glycoproteins and glycolipids (Poo and Robinson, 1977), the acetylcholine receptor (Orida and Poo, 1978; Stollberg and Fraser, 1988), the LDL receptor (Tank et al., 1985), the IgG receptor (Ryan et al., 1988), and the EGF receptor (Zhao et al., 1999a). A proposed solution to this anomaly was that a second, overwhelming 
force next to the plasma membrane moved cell-surface molecules in the opposite direction. Specifically, water flow in the extracellular boundary layer, induced by electroosmosis, was driving cathodal movement of freely diffusing surface molecules and overwhelming electrophoresis to the anode (McLaughlin and Poo, 1981). Most cells carry a net negative surface charge such that mobile cations (mostly $\mathrm{Na}^{+}$) are concentrated in the surface boundary layer and anions are excluded. In an applied EF, current flow near the extracellular boundary layer is carried predominantly by mobile cations that drag along their shell of hydration (water) toward the cathode (Fig. 6, bottom). This gives rise to water flow toward the cathode, within the extracellular boundary layer, and produces a physical force driving surface molecules to the cathode (McLaughlin and Poo, 1981). Electro-osmosis is a phenomenon that is commonly employed for chemical separations within glass capillaries that posses a negative surface charge. Removal of the negative surface charge eliminates the electro-osmotic force. Reduction of the negative surface charge of cells by removing the abundant negatively charged sialic acids from the cell surface with neuraminidase or by adding a cationic lipid, DiI, should therefore reduce the electro-osmotic flow (EOF) of water and decrease cathodal localization of surface molecules. These treatments did in fact lead to the redirection of cell-surface proteins to the anode, favoring the hypothesis that in the absence of electro-osmosis, electrophoresis of the negatively charged proteins becomes the overwhelming directing force (McLaughlin and Poo, 1981).

While many reports have shown the asymmetric distribution of surface proteins in response to applied EFs, only two attempts have been made to alter cell-surface charge and monitor the directed growth or migration of cells. Addition of neuraminidase did not alter the cathodal growth of Xenopus spinal neurites (McCaig, 1989) but did reduce the cathodal migration of 3T3 fibroblasts and HeLa cells by $\sim 33 \%$ (Finkelstein et al., 2007). Addition of cationic avidin to cell surfaces appeared to reduce the net surface charge but did not alter their EF-directed cathodal migration (Finkelstein et al., 2007). It must be explained that the results due to the use of neuraminidase are difficult to interpret because culture conditions must be optimized to enable peak enzyme activity. Neuraminidase from Clostridium perfringens (Cassidy et al., 1965) and Vibrio cholera (Ada et al., 1961) has a pH optimum near 5.6 in phosphate or Tris buffers, with nearly 10-fold lower activity above $\mathrm{pH} 7.5$. Poo et al. (1979) obtained reversal of migration of surface proteins on muscle cells by incubating them in $0.1 \mathrm{U} / \mathrm{ml}$ of neuraminidase for $1 \mathrm{~h}$ at $\mathrm{pH}$ 6.6. Finkelstein et al. (2007) incubated NIH 3 T3 and HeLa cells in $10 \mathrm{U} / \mathrm{mL}$ of neuraminidase at $\mathrm{pH} 7.3$ for $1 \mathrm{~h}$ to obtain a $33 \%$ reduction in the number of cells that migrated cathodally. Finkelstein et al. (2007) attempted to maintain neuraminidase in the medium during application of the EF, but cells still appeared to recover surface sialic acids very quickly, so that within $1 \mathrm{~h}$ the amount of surface sialic acids was not different from that of untreated control cells. The lack of modified cathodal growth by Xenopus neurites may have been due to the very low activity of neuraminidase that was applied for only $0.5-1 \mathrm{~h}$ to the cells that were cultured at alkaline $\mathrm{pH}$ 7.8-8.0 (McCaig, 1989). The role of sialic acids in electroosmosis and galvanotaxis could be more carefully studied on a model system that migrates at acidic $\mathrm{pH}$ where neuraminidase can more readily facilitate their removal.

Alteration of surface charge using the cationic fluorescent membrane dye, DiI, also reversed migration of cell-surface proteins from the cathode to the anode (McLaughlin and Poo, 1981). This treatment does not appear to have been used to attempt to alter direction of cell migration, but it did completely abolish the perpendicular alignment of muscle cells to applied electric fields (McCaig and Dover, 1991).

Multivalent inorganic ions are known to reduce net negative charge on the surface of cells as well as on the proteins themselves (Obi et al., 1989; Besteman et al., 2004). While $\mathrm{Co}^{2+}, \mathrm{La}^{3+}$, and $\mathrm{Gd}^{3+}$ have been used to inhibit or reverse directed migration and growth, their use has not been interpreted as being linked to alteration of surface charge but rather to blockage of plasma membrane $\mathrm{Ca}^{2+}$ channels (Cooper and Schliwa, 1986; McCaig, 1989; Huang et al., 2009) (more below). Multivalent ions alter cell-surface charge and net protein charge in a manner that makes it difficult to predict their net effect.

It can be envisioned how the asymmetric redistribution of cell-surface proteins could provide a directional signal. On the other hand, this phenomenon may simply be an irrelevant side effect of the external electric field. Pretreatment of muscle cells with concanavalin A prevented asymmetric distribution of Con A receptors in an applied EF (Poo et al., 1979). However, the same treatment did not prevent the perpendicular alignment of muscle cells in the field (McCaig and Dover, 1991). Also, reduction of electro-osmotic water flow by increasing viscosity had no effect in altering the directed growth of neurites in applied EF (Jaffe and Poo, 1979). As intriguing as the idea may be that the interplay between electrophoresis and electro-osmosis controls EFdirected migration and growth, there is very little evidence to support it.

\section{Asymmetric membrane potential}

The second mechanism by which vertebrate cells are thought to sense DC EFs invokes polarized activation of plasma membrane voltage sensors. Most efforts have been directed toward determining the role of voltage-sensitive $\mathrm{Ca}^{2+}$ channels. According to this hypothesis, asymmetric polarization of membrane potential occurs when the plasma membrane on the cathode (negative pole) facing side of the cell is relatively depolarized compared to the anodal side 


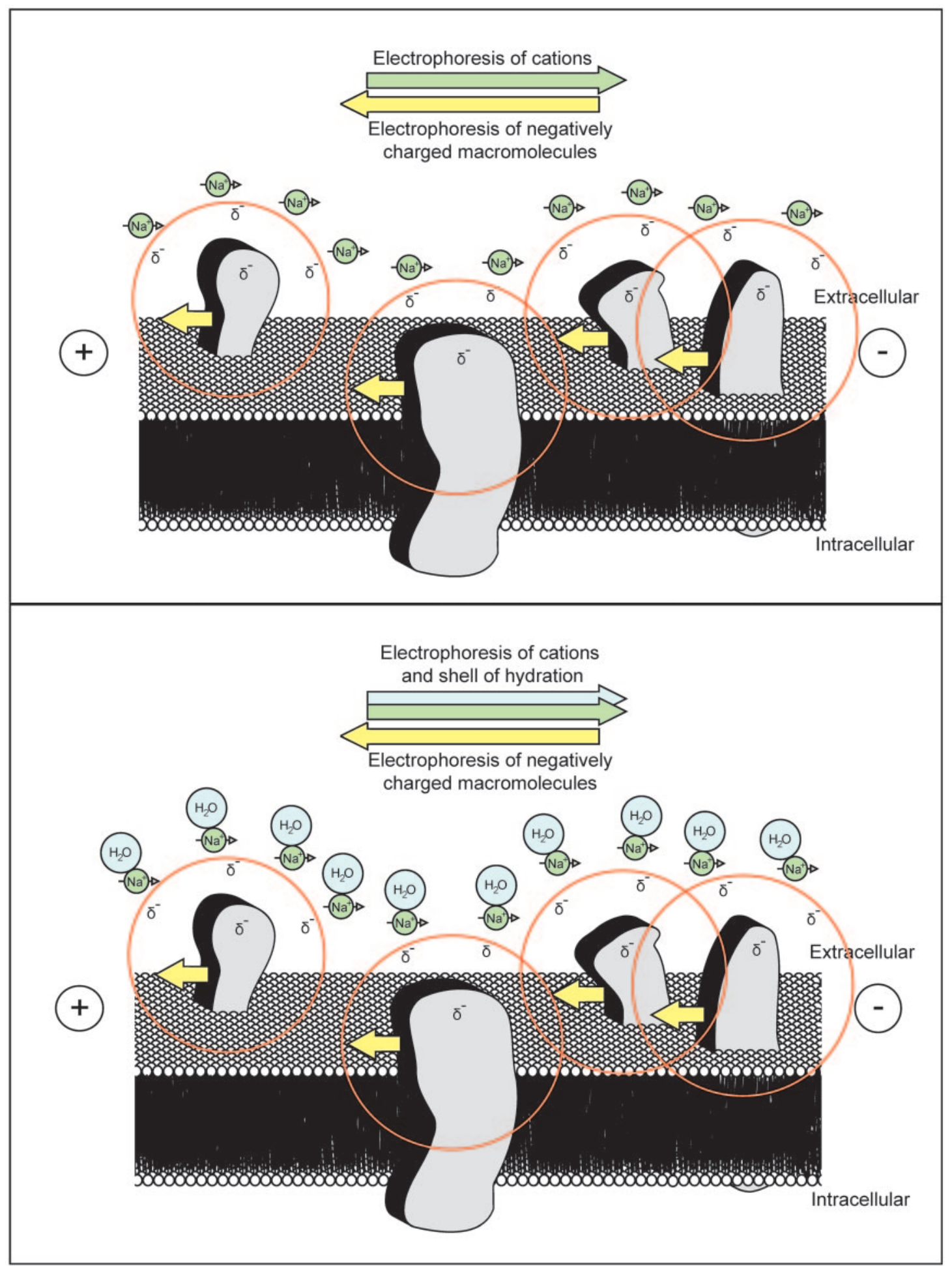

Figure 6. Applied electric fields generate electrophoretic and electro-osmotic forces on charged species in the extracellular boundary layer. (Top) In the extracellular boundary layer of the plasma membrane, shown in this cross-section, an external EF generates an electrophoretic force on charged species. Macromolecules with a net negative surface charge are forced toward the anode, while highly abundant extracellular cations, primarily $\mathrm{Na}^{+}$, are forced toward the cathode. Arrows indicate the direction of the electrical force on charged species. Radiating circles around proteins signify relative negative charge distribution. (Bottom) Migrating cations drag their shell of hydration (water flow), generating an electro-osmotic force that overwhelms the electrophoretic force and moves cell-surface macromolecules to the cathode (McLaughlin and Poo, 1981). 
(positive pole), which will be slightly hyperpolarized. The depolarized membrane on the cathodal side could then give rise to increased $\mathrm{Ca}^{2+}$ influx on the cathodal side due to activation of voltage-gated $\mathrm{Ca}^{2+}$ channels, thereby generating a high gradient of intracellular $\mathrm{Ca}^{2+}$ at the cathode that could be used to direct cathodal migration and growth (reviewed in Robinson, 1985). Even as this hypothesis was proposed, it was noted that the available evidence argued against it because voltage-gated channels require large depolarizing changes in membrane potential, tens of millivolts more positive, before opening. The small electrical potential differences, $0.1-0.2 \mathrm{mV}$, that exist at the threshold of the EF-induced response are not sufficient to activate voltagegated $\mathrm{Ca}^{2+}$ channels to any great extent (reviewed in Robinson, 1985). However, the mechanism found favor and is still embraced owing to a number of findings showing that blockage of plasma membrane $\mathrm{Ca}^{2+}$ channels with organic or inorganic blockers reduces or eliminates the galvanotactic responses (reviewed in McCaig et al., 2005). The inorganic blockers are multivalent ions, including $\mathrm{Co}^{2+}, \mathrm{La}^{3+}$, and $\mathrm{Gd}^{3+}$. As discussed above, these blockers may exert their effects by modifying surface charge and altering electro-osmotic flow. However, there is no alternate explanation for why the organic $\mathrm{Ca}^{2+}$ channel blockers reduce or eliminate galvanotaxis.

The paradox inherent in this hypothesis is generated by pre-existing data on the intracellular $\mathrm{Ca}^{2+}$ gradients present during cell motility. In applied EFs, voltage-gated $\mathrm{Ca}^{2+}$ channels may be opened more often by the depolarizing potential on the cathodal side. Therefore, cells migrating toward the cathode should have a cathode high $\left[\mathrm{Ca}^{2+}\right]_{\mathrm{i}}$ on the leading edge of the cell. This proposed $\mathrm{Ca}^{2+}$ gradient is backward to a majority of findings in which it is the trailing edge of migrating cells that has the high $\left[\mathrm{Ca}^{2+}\right]_{\mathrm{i}}$, as shown in studies of amoeba, fibroblasts, kidney epithelial tumor cells, vascular endothelial cells, and prostate tumor cells (reviewed in Maroto and Hamill, 2007) and in migrating zebrafish keratocytes (Huang et al., 2009). How can this hypothesis hold up if the EF-induced $\mathrm{Ca}^{2+}$ influx and the steady, high $\left[\mathrm{Ca}^{2+}\right]_{\mathrm{i}}$ are on opposite sides of the cells? More recent evidence may provide an answer. These results indicate that $\mathrm{Ca}^{2+}{ }_{i}$ signaling occurs at the leading edge of motile cells and that the gradient is not steady but fluctuates in space and time (Evans and Falke, 2007; Wei et al., 2009). Earlier reports may not have been able to capture or analyze the $\mathrm{Ca}^{2+}{ }_{\mathrm{i}}$ transients at the leading edge. Therefore, a more careful time-lapse analysis of $\mathrm{Ca}^{2+}{ }_{\mathrm{i}}$ gradients must be performed on cells migrating in an applied EF.

Evidence contrary to the asymmetric $\mathrm{Ca}^{2+}$ influx theory is that fish keratocytes (Cooper and Schliwa, 1986) and mouse fibroblasts (Brown and Loew, 1994) apparently do not posses voltage-gated $\mathrm{Ca}^{2+}$ channels in the plasma membrane. Also, in the absence of extracellular $\mathrm{Ca}^{2+}$, human keratinocytes (Nishimura et al., 1996), zebrafish keratocytes
(Huang et al., 2009), mouse fibroblasts (Brown and Loew, 1994), and Xenopus embryonic spinal neurites (Palmer et al., 2000) display directed migration and growth toward the cathode that is similar in extent to when $\mathrm{Ca}^{2+}$ was present. The absence of $\mathrm{Ca}^{2+}$, of course, really refers to very low $\mathrm{Ca}^{2+}$, such as $<1 \mathrm{nmol} 1^{-1}$ (Palmer et al., 2000) and $<10$ nmol $1^{-1}$ (Huang et al., 2009) where the electrochemical driving force for $\mathrm{Ca}^{2+}$ across the plasma membrane is near equilibrium, resulting in no net movement of $\mathrm{Ca}^{2+}$ and no changes in intracellular $\mathrm{Ca}^{2+}$. Similarly, restricting changes in $\mathrm{Ca}^{2+}{ }_{\mathrm{i}}$ with cell-permeant forms of the $\mathrm{Ca}^{2+}$ buffer BATPA did not alter cathodal migration or growth (Palmer et al., 2000; Huang et al., 2009). However, it must be recognized that when $\mathrm{Ca}^{2+}$ is present, it may be the common second messenger used to transduce the EF signal. Migratory cells lose polarity and show decreased rates of migration in the absence of $\mathrm{Ca}^{2+}$ (Nishimura et al., 1996; Huang et al., 2009). Therefore, although $\mathrm{Ca}^{2+}{ }_{\mathrm{i}}$ signaling is not strictly required for EF-directed motility, when present it appears to act in a supporting role and may act in a controlling role.

The hypothesis of asymmetric activation of ion channels during galvanotaxis has been extended to voltage-gated $\mathrm{Na}^{+}$channels (Djamgoz et al., 2001) and other voltagesensitive proteins such as phosphatases. However, the voltage-dependence of these proteins is similarly insensitive to the weak potential differences that exist across cells at the threshold of response, as in the voltage-gated $\mathrm{Ca}^{2+}$ channels mentioned above. The single voltage-sensitive phosphatase that has been characterized has a half-maximal activation potential of $+62.7 \mathrm{mV}$ and does not appear to be voltagesensitive below $-20 \mathrm{mV}$ (Murata et al., 2005)—tens of millivolts more positive than most resting membrane potentials.

\section{Conclusions}

Many different forms of extracellular signaling cues are used during development, regeneration, and wound healing to generate pattern and organization. An understanding of these natural signals provides us with a basis for mimicking-even optimizing - them to engineer elaborate multicellular tissues and organs. Endogenous EFs are one such signaling cue that has been characterized in developing and regenerating systems and used in the clinic to treat chronic wounds and spinal injury. At this point, such treatment of chronic wounds has worked when other treatments have failed. However, the mechanisms by which the fields improve healing are not known, making it difficult to substantiate use of any specific form of ES and preventing optimization of treatment. Current research has identified downstream molecular signaling pathways that are involved with remodeling cells during directed migration in response to EFs, but the mechanisms for sensing weak DC EFs 
remain unknown. A thorough understanding of these sensing mechanisms will enable clinicians and engineers to apply a wider degree of EF modulation for rebuilding tissues and organs in vivo and in vitro.

\section{Acknowledgments}

This work has been supported by The Eugene and Millicent Bell Fellowship Fund in Tissue Engineering (M.A.M.), the Hermann Foundation Research Development Fund Award (M.A.M.), the NIH:NCRR grant P41 RR001395 (PI Peter JS Smith) and the Regenerative Biology Center at the MBL GM092374 (PI Gary Borisy). We thank Ken Robinson for providing the pictures of Xenopus developmemt.

\section{Literature Cited}

Ada, G. L., E. L. French, and P. E. Lind. 1961. Purification and properties of neuraminidase from Vibrio cholerae. J. Gen. Microbiol. 24: 409-421.

Alexander, J. K., B. Fuss, and R. J. Colello. 2006. Electric fieldinduced astrocyte alignment directs neurite outgrowth. Neuron Glia Biol. 2: $93-103$

Altizer, A. M., S. G. Stewart, B. K. Albertson, and R. B. Borgens. 2002. Skin flaps inhibit both the current of injury at the amputation surface and regeneration of that limb in newts. J. Exp. Zool. 293: 467-477.

Atkinson, D. L., T. J. Stevenson, E. J. Park, M. D. Riedy, B. Milash, and S. J. Odelberg. 2006. Cellular electroporation induces dedifferentiation in intact newt limbs. Dev. Biol. 299: 257-271.

Baker, L. L., R. Chambers, S. K. DeMuth, and F. Villar. 1997. Effects of electrical stimulation on wound healing in patients with diabetic ulcers. Diabetes Care 20: 405-412.

Barker, A. T., L. F. Jaffe, and J. W. Vanable, Jr. 1982. The glabrous epidermis of cavies contains a powerful battery. Am. J. Physiol. Regul. Integr. Comp. Physiol. 242: 358-366.

Besteman, K., M. A. G. Zevenbergen, H. A. Heering, and S. G. Lemay. 2004. Direct observation of charge inversion by multivalent ions as a universal electrostatic phenomenon. Phys. Rev. Lett. 93: 170802-1170802-4.

Borgens, R. B., J. W. Vanable, Jr., and L. F. Jaffe. 1977a. Bioelectricity and regeneration. I. Initiation of frog limb regeneration by minute currents. J. Exp. Zool. 200: 403-416.

Borgens, R. B., J. W. J. Vanable, and L. F. Jaffe. 1977b. Bioelectricity and regeneration: large currents leave the stumps of regenerating newt limbs. Proc. Natl. Acad. Sci. USA 74: 4528-4532.

Borgens, R. B., J. W. J. Vanable, and L. F. Jaffe. 1979a. Reduction of sodium dependent stump currents disturbs urodele limb regeneration. J. Exp. Zool. 209: 377-386.

Borgens, R. B., J. W. Vanable, Jr., and L. F. Jaffe. 1979b. Small artificial currents enhance Xenopus limb regeneration. J. Exp. Zool. 207: 217-226.

Borgens, R. B., L. F. Jaffe, and M. J. Cohen. 1980. Large and persistent electrical currents enter the transected lamprey spinal cord. Proc. Natl. Acad. Sci. USA 77: 1209-1213.

Borgens, R. B., E. Roederer, and M. J. Cohen. 1981. Enhanced spinal cord regeneration in lamprey by applied electric fields. Science 213: 611-617.

Borgens, R. B., A. R. Blight, and D. J. Murphy. 1986. Transected dorsal column axons within the guinea pig spinal cord regenerate in the presence of an applied electric field. J. Comp. Neurol. 250: 168-180.

Borgens, R. B., A. R. Blight, and M. E. McGinnis. 1987. Behavioral recovery induced by applied electric fields after spinal cord hemisection in guinea pig. Science 238: 366-369.

Borgens, R. B., R. Shi, T. J. Mohr, and C. B. Jaeger. $1994 . \quad$ Mammalian cortical astrocytes align themselves in a physiological voltage gradient. Exp. Neurol. 128: 41-49.

Borgens, R. B., J. P. Toombs, G. Breur, W. R. Widmer, D. Waters, A. M. Harbath, P. March, and L. G. Adams. 1999. An imposed oscillating electrical field improves the recovery of function in neurologically complete paraplegic dogs. J. Neurotrauma 16: 639-657.

Brown, M. J., and L. M. Loew. 1994. Electric field-directed fibroblast locomotion involves cell surface molecular reorganization and is calcium independent. J. Cell Biol. 127: 117-128.

Carley, P. J., and S. F. Wainapel. 1985. Electrotherapy for acceleration of wound healing: low intensity direct current. Arch. Phys. Med. Rehabil. 66: 443-446.

Cassidy, J. T., G. W. Jourdian, and S. Roseman. 1965. The sialic acids. VI. Purification and properties of sialidase from Clostridium perfringens. J. Biol. Chem. 240: 3501-3506.

Chao, P.-h. G., R. Roy, R. L. Mauck, W. Liu, W. B. Valhmu, and C. T. Hung. 2000. Chondrocyte translocation response to direct current electric fields. J. Biomech. Eng. 122: 261-267.

Chao, P.-h. G., H. H. Lu, C. T. Hung, S. B. Nicoll, and J. C. Bulinski. 2007. Effects of applied DC electric field on ligament fibroblast migration and wound healing. Connect. Tissue Res. 48: 188-197.

Chernyavsky, A. I., J. Arredondo, E. Karlsson, I. Wessler, and S. A. Grando. 2005. The Ras/Raf-1/MEK1/ERK signaling pathway coupled to integrin expression mediates cholinergic regulation of keratinocyte directional migration. J. Biol. Chem. 280: 39220-39228.

Chiang, M., E. J. Cragoe, Jr., and J. W. Vanable, Jr. 1989. Electrical fields in the vicinity of small wounds in Notophthalmus viridescens skin. Biol. Bull. 176: 179-183.

Chiang, M., E. J. Cragoe, Jr., and J. W. Vanable, Jr. 1991. Intrinsic electric fields promote epithelialization of wounds in the newt, Notophthalmus viridescens. Dev. Biol. 146: 377-385.

Chiang, M., K. R. Robinson, and J. W. Vanable, Jr. 1992. Electrical fields in the vicinity of epithelial wounds in the isolated bovine eye. Exp. Eye Res. 54: 999-1003.

Cooper, M. S., and R. E. Keller. 1984. Perpendicular orientation and directional migration of amphibian neural crest cells in dc electrical fields. Proc. Natl. Acad. Sci USA 81: 160-164.

Cooper, M. S., and M. Schliwa. 1986. Motility of cultured fish epidermal cells in the presence and absence of direct current electric fields. J. Cell Biol. 102: 1384-1399.

Cork, R. J., M. E. McGinnis, J. Tsai, and K. R. Robinson. 1994. The growth of PC12 neurites is biased toward the anode. J. Neurobiol. 25: $1609-1616$.

Cormie, P., and K. R. Robinson. 2007. Embryonic zebrafish neuronal growth is not affected by an applied electric field in vitro. Neurosci. Lett. 411: 128-132.

Davenport, R. W., and C. D. McCaig. 1993. Hippocampal growth cone responses to focally applied electric fields. Dev. Neurobiol. 24: 89-100.

Djamgoz, M. B. A., M. Mycielska, Z. Madeja, S. P. Fraser, and W. Kohorada. 2001. Directional movement of rat prostate cancer cells in direct-current electric field: involvement of voltage-gated $\mathrm{Na}^{+}$channel activity. J. Cell Sci. 114: 2697-2705.

du Bois-Reymond, E. 1860. Untersuchungen über tierische Elektrizität. Vol. II, pp. 2-68. Reimer, Berlin.

Evans, J. H., and J. J. Falke. 2007. $\mathrm{Ca}^{2+}$ influx is an essential component of the positive-feedback loop that maintains leading-edge structure and activity in macrophages. Proc. Natl. Acad. Sci. USA 104: 16176-16181.

Fehlings, M. G., C. H. Tator, and R. D. Linden. 1988. The effect of 
direct-current field on recovery from experimental spinal cord injury. J. Neurosurg. 68: 781-792.

Ferrier, J., S. M. Ross, J. Kanehisa, and J. E. Aubin. $1986 . \quad$ Osteoclasts and osteoblasts migrate in opposite directions in response to a constant electrical field. J. Cell. Physiol. 129: 283-288.

Finkelstein, E. I., P.-h. G. Chao, C. T. Hung, and J. C. Bulinski. 2007. Electric field-induced polarization of charged cell surface proteins does not determine the direction of galvanotaxis. Cell Motil. Cytoskel. 64: 833-846.

Gardner, S. E., R. A. Frantz, and F. L. Schmidt. 1999. Effect of electrical stimulation on chronic wound healing: a meta-analysis. Wound Repair Regen. 7: 495-503.

Gault, W. R., and P. F. J. Gatens. 1976. Use of low intensity direct current in management of ischemic skin ulcers. Phys. Ther. 56: 265269.

Gehl, J., T. H. Sorensen, K. Nielsen, P. Raskmark, S. L. Nielsen, T. Skovsgaard, and L. M. Mir. 1999. In vivo electroporation of skeletal muscle: threshold, efficacy and relation to electric field distribution. Biochim. Biophys. Acta 1428: 233-240.

Godbout, C., and J. Frenette. 2006. Periodic direct current does not promote wound closure in an in vitro dynamic model of cell migration. Phys. Ther. 86: 51-59.

Guo, A., B. Song, B. Reid, Y. Gu, J. V. Forrester, C. A. B. Jahoda, and M. Zhao. 2010. Effects of physiological electric fields on migration of human dermal fibroblasts. J. Invest. Dermatol. 130: 2320-2327.

Herlitzka, A. 1910. Ein Beitrag zur Physiologie der Regeneration. Roux's Arch. Dev. Biol. 10: 126-158.

Hinkle, L., C. D. McCaig, and K. R. Robinson. 1981. The direction of growth of differentiating neurones and myoblasts from frog embryos in an applied electric field. J. Physiol. 314: 121-135.

Hotary, K. B., and K. R. Robinson. 1990. Endogenous electrical currents and the resultant voltage gradients in the chick embryo. Dev. Biol. 140: $149-160$.

Hotary, K. B., and K. R. Robinson. 1992. Evidence of a role for endogenous electrical fields in chick embryo development. Development 114: 985-996.

Hotary, K. B., and K. R. Robinson. 1994. Endogenous electrical currents and voltage gradients in Xenopus embryos and the consequences of their disruption. Dev. Biol. 166: 789-800.

Huang, L., P. Cormie, M. A. Messerli, and K. R. Robinson. 2009. The involvement of $\mathrm{Ca}^{2+}$ and integrins in directional responses of zebrafish keratocytes to electric fields. J. Cell. Physiol. 219: 162-172.

Illingworth, C. M., and A. T. Barker. 1980. Measurement of electrical currents emerging during the regeneration of amputated finger tips in children. Clin. Phys. Physiol. Meas. 1: 87-89.

Ingvar, D. 1947. Experiments on the influence of electric current upon growing nerve cell processes in vitro. Acta Physiol. Scand. 13: 150154.

Ingvar, S. 1920. Reaction of cells to the galvanic current in tissue cultures. Proc. Soc. Exp. Biol. Med. 17: 198-199.

Jaffe, L. F. 1977. Electrophoresis along cell membranes. Nature 265: 600-602.

Jaffe, L. F., and M.-M. Poo. 1979. Neurites grow faster towards the cathode than the anode in a steady field. J. Exp. Zool. 209: 115-128.

Jaffe, L. F., and C. D. Stern. 1979. Strong electrical currents leave the primitive streak of chick embryos. Science 206: 569-571.

Jenkins, L. S., B. S. Duerstock, and R. B. Borgens. 1996. Reduction of the current of injury leaving the amputation inhibits limb regeneration in the red spotted newt. Dev. Biol. 178: 251-262.

Jennings, J. A., D. Chen, and D. S. Feldman. 2010. Upregulation of chemokine (C-C motif) ligand 20 in adult epidermal keratinocytes in direct current electric fields. Arch. Dermatol. Res. 302: 211-220.

Kloth, L. C. 2005. Electrical stimulation for wound healing: a review of evidence from in vitro studies, animal experiments, and clinical trials. Int. J. Low. Extrem. Wounds 4: 23-44.

Levin, M. 2007. Large-scale biophysics: ion flow and regeneration. Trends Cell Biol. 17: 261-270.

Lundeberg, T. C. M., S. V. Eriksson, and M. Malm. 1992. Electrical nerve stimulation improves healing of diabetic ulcers. Ann. Plast. Surg. 29: $328-331$.

Maroto, R., and O. P. Hamill. 2007. MscCa regulation of tumor cell migration and metastasis. Pp. 485-509 in Current Topics in Membranes, Vol. 59, Mechanosensitive Ion Channels, Part B, O. P. Hamill, ed. Academic Press, San Diego.

Marsh, G., and H. W. Beams. 1946. In vitro control of growing chick nerve fibers by applied electric fields. J. Cell. Comp. Physiol. 27: $139-157$.

McCaig, C. D. 1987. Spinal neurite reabsorption and regrowth in vitro depend on the polarity of an applied electric field. Development 100: 31-41.

McCaig, C. D. 1989. On the mechanism of nerve galvanotropism. Biol. Bull. 176: 136-139.

McCaig, C. D., and P. J. Dover. 1991. Factors influencing perpendicular elongation of embryonic frog muscle cells in a small applied electric field. J. Cell Sci. 98: 497-506.

McCaig, C. D., A. M. Rajnicek, B. Song, and M. Zhao. 2005. Controlling cell behavior electrically: current views and future potential. Physiol. Rev. 85: 943-978.

McGinnis, M. E., and J. W. Vanable, Jr. 1986. Electrical fields in Notophthalmus viridescens limb stumps. Dev. Biol. 116: 184-193.

McKasson, M. J., L. Huang, and K. R. Robinson. 2008. Chick embryonic Schwann cells migrate anodally in small electrical fields. Exp. Neurol. 211: 585-587.

McLaughlin, S. M., and M.-M. Poo. 1981. The role of electro-osmosis in the electric-field-induced movement of charged macromolecules on the surfaces of cells. Biophys. J. 34: 85-93.

Murata, Y., H. Iwasaki, M. Sasaki, K. Inaba, and Y. Okamura. 2005. Phosphoinositide phosphatase activity coupled to an intrinsic voltage sensor. Nature 435: 1239-1243.

Nishimura, K. Y., R. R. Isseroff, and R. Nuccitelli. 1996. Human keratinocytes migrate to the negative pole in direct current electrical fields comparable to those measured in mammalian wounds. J. Cell Sci. 109: 199-207.

Obi, I., Y. Ichikawa, T. Kakutani, and M. Senda. 1989. Electrophoresis, zeta potential and surface charges of barley mesophyll protoplasts. Plant Cell Physiol. 30: 129-135.

Orida, N., and M.-M. Poo. 1978. Electrophoretic movement and localisation of acetycholine receptors in the embryonic muscle cell membrane. Nature 275: 31-35.

Palmer, A. M., M. A. Messerli, and K. R. Robinson. 2000. Neuronal galvanotropism is independent of external $\mathrm{Ca}^{2+}$ entry or internal $\mathrm{Ca}^{2+}$ gradients. J. Neurobiol. 45: 30-38.

Pan, L., and R. B. Borgens. 2010. Perpendicular organization of sympathetic neurons within a required physiological voltage. Exp. Neurol. 222: 161-164.

Patel, N. B., and M.-M. Poo. 1982. Orientation of neurite growth by extracellular electric fields. J. Neurosci. 2: 483-496.

Poo, M.-M., and K. R. Robinson. 1977. Electrophoresis of concanavalin A receptors along embryonic muscle cell membrane. Nature $\mathbf{2 6 5}$ : 602-605.

Poo, M.-M., J. W. Lam, N. Orida, and A. W. Chao. 1979. Electrophoresis and diffusion in the plane of the cell membrane. 26: 1-22.

Posterino, G. S., G. D. Lamb, and D. G. Stephenson. 2000. Twitch and tetanic force responses and longitudinal propagation of action potentials in skinned skeletal muscle fibres of the rat. J. Physiol. 527: 131-137.

Rajnicek, A. M., R. F. Stump, and K. R. Robinson. $1988 . \quad$ An 
endogenous sodium current may mediate wound healing in Xenopus neurulae. Dev. Biol. 128: 290-299.

Rajnicek, A. M., N. A. R. Gow, and C. D. McCaig. 1992. Electric field-induced orientation of rat hippocampal neurones in vitro. Exp. Physiol. 77: 229-232.

Rajnicek, A. M., K. R. Robinson, and C. D. McCaig. 1998. The direction of neurite growth in a weak DC electric field depends on the substratum: contributions of adhesivity and net surface charge. Dev. Biol. 203: 412-423.

Reid, B., S. Bing, C. D. McCaig, and M. Zhao. 2005. Wound healing in rat cornea: the role of electric currents. FASEB J. 19: 379-386.

Rhodes, L. R., J. J. Turek, E. J. Cragoe, and J. W. Vanable. 1990. Wound currents and wound healing in the newt, Notophthalmus viridescens. Roux's Arch. Dev. Biol. 198: 355-362.

Robinson, K. R. 1985. The responses of cells to electrical fields: A review. J. Cell Biol. 101: 2023-2027.

Robinson, K. R., and P. Cormie. 2008. Electric field effects on human spinal injury: Is there a basis in the in vitro studies? Dev. Neurobiol. 68: 274-280.

Robinson, K. R., and R. F. Stump. 1984. Self-generated electrical currents through Xenopus neurulae. J. Physiol. 352: 339-352.

Ryan, T. A., J. Myers, D. Holowka, B. Baird, and W. W. Webb. 1988. Molecular crowding on the cell surface. Science 239: 61-64.

Shapiro, S., R. Borgens, R. Pascuzzi, K. Roos, M. Groff, S. Purvines, R. B. Rodgers, S. Hagy, and P. Nelson. 2005. Oscillating field stimulation for complete spinal cord injury in humans: a Phase I trial. J. Neurosurg. Spine 2: 3-10.

Sillman, A. L., D. M. Quang, B. Farboud, K. S. Fang, R. Nuccitelli, and R. R. Isseroff. 2003. Human dermal fibroblasts do not exhibit directional migration on collagen I in direct-current electric fields of physiological strength. Exp. Dermatol. 12: 396-402.

Song, B., M. Zhao, J. V. Forrester, and C. D. McCaig. 2002. Electrical cues regulate the orientation and frequency of cell division and the rate of wound healing in vivo. Proc. Natl. Acad. Sci. USA 99: $13577-13582$.

Song, B., M. Zhao, J. Forrester, and C. D. McCaig. 2004. Nerve regeneration and wound healing are stimulated and directed by an endogenous electrical field in vivo. J. Cell Sci. 117: 4681-4690.

Sta Iglesia, D. D., and J. W. Vanable, Jr. 1998. Endogenous lateral electric fields around bovine corneal lesions are necessary for and can enhance normal rates of wound healing. Wound Repair Regen. 6: 531-542.

Sta Iglesia, D. D., E. J. Cragoe, and J. W. Vanable, Jr. 1996. Electric field strength and epithelialization in the newt (Notophthalmus viridescens). J. Exp. Zool. 274: 56-62.

Stollberg, J., and S. E. Fraser. 1988. Acetylcholine receptors and
concanavalin-A-binding sites on cultured Xenopus muscle cells: electrophoresis, diffusion and aggregation. J. Cell Biol. 107: 1397-1408.

Tank, D. W., W. J. Fredericks, L. S. Barak, and W. W. Webb. 1985. Electric-field induced redistribution and post-field relaxation of lowdensity lipoprotein receptors on cultured human fibroblasts. J. Cell Biol. 101: 148-157.

Watson, T. 2008. Electrical stimulation for enhanced wound healing. Pp. 329-346 in Electrotherapy: Evidence-based Practice, 12th ed., T. Watson, ed. Churchill Livingstone, New York.

Wei, C., X. Wang, M. Chen, K. Ouyang, L.-S. Song, and H. Cheng. 2009. Calcium flickers steer cell migration. Nature 457: 901-906.

Weiss, P. 1934. In vitro experiments on the factors determining the course of the outgrowing nerve fiber. J. Exp. Zool. 68: 393-448.

Williams, S. C. 1936. A study of the reactions of growing embryonic nerve fibers to the passage of direct current through the surrounding medium. Anat. Rec. 64: 56-57.

Winkel, G. K., and R. Nuccitelli. 1989. Large ionic currents leave the primitive streak of the 7.5-day mouse embryo. Biol. Bull. 176: 110117.

Wolcott, L. E., P. C. Wheeler, H. M. Hardwicke, and B. A. Rowley. 1969. Accelerated healing in skin ulcers by electrotherapy. South. Med. J. 62: 795-801.

Zhao, M. 2009. Electrical fields in wound healing — an overriding signal that directs cell migration. Semin. Cell Dev. Biol. 20: 674-682.

Zhao, M., A. Agius-Fernandez, J. V. Forrester, and C. D. McCaig. 1996. Orientation and directed migration of cultured corneal epithelial cells in small electric fields are serum dependent. J. Cell Sci. 109: $1405-1414$.

Zhao, M., A. Dick, J. V. Forrester, and C. D. McCaig. 1999a. Electric field-directed cell motility involves up-regulated expression and asymmetric redistribution of the epidermal growth factor receptors and is enhanced by fibronectin and laminin. Mol. Biol. Cell 10: 1259-1276.

Zhao, M., J. V. Forrester, and C. D. McCaig. 1999b. A small, physiological electric field orients cell division. Proc. Natl. Acad. Sci. USA 96: 4942-4946.

Zhao, M., H. Bai, E. Wang, J. V. Forrester, and C. D. McCaig. 2004. Electrical stimulation directly induces pre-angiogenic responses in vascular endothelial cells by signaling through VEGF receptor. J. Cell Sci. 117: 397-405.

Zhao, M., B. Song, J. Pu, T. Wada, B. Reid, G. Tai, F. Wang, A. Guo, P. Walczysko, Y. Gu, et al. 2006. Electrical signals control wound healing through phosphatidylinositol-3-OH kinase- $\gamma$ and PTEN. Nature 442: 457-460.

Zuberi, M., P. Liu-Snyder, A. ul Haque, D. M. Porterfield, and R. B. Borgens. 2008. Large naturally-produced electric currents and voltage traverse damaged mammalian spinal cord. J. Biol. Eng. 2: 17. 